Article

\title{
An Economic Penalty Scheme for Optimal Parking Lot Utilization with EV Charging Requirements
}

\author{
Ruifeng Shi ${ }^{1,2, *}$, Jie Zhang ${ }^{1}{ }^{(}$, Hao Su ${ }^{1,2} \mathbb{D}$, Zihang Liang ${ }^{3}$ and Kwang Y. Lee ${ }^{4}$ \\ 1 School of Control and Computer Engineering, North China Electric Power University, Beijing 102206, China; \\ zhang.jie@ncepu.edu.cn (J.Z.); su.hao@ncepu.edu.cn (H.S.) \\ 2 China Institute of Energy and Transportation Integrated Development, Beijing 102206, China \\ 3 Guangdong Pumped Storage Power Generation Co., Ltd., Guangzhou 510635, China; zihleung@hotmail.com \\ 4 Department of Electrical and Computer Engineering, Baylor University, Waco, TX 76798, USA; \\ kwang_y_lee@baylor.edu \\ * Correspondence: shi.ruifeng@ncepu.edu.cn; Tel.: +86-10-6177-2027
}

Received: 14 October 2020; Accepted: 20 November 2020; Published: 23 November 2020

check for updates

\begin{abstract}
In the parking lots of public commercial areas, such as shopping malls, hospitals, and scenic spots, the parking spaces with electric vehicle (EV) charging facilities are often occupied by ordinary cars. How to regulate the parking order in the parking lot is a key issue in the operation and management of the parking facilities. In this paper, a method of assessing parking fees for vehicles parked at the charging facilities is proposed based on an economic penalty strategy, including fixed-penalty and dynamic-penalty strategies. First, a traffic flow model of the parking lot in public area is established. Then, a price and consumption model of parking fees and parking lot utilization is established, along with different penalty strategies. Finally, taking the parking lot of a shopping mall as an example, the penalty strategies are optimized through particle swarm optimization (PSO) algorithm. The simulation results show that the method proposed can help to improve the utilization of EV charging facilities in parking lots and guide the orderly parking and charging of EVs at the same time.
\end{abstract}

Keywords: electric vehicles charging; public area orderly parking and charging; economic penalty model; price and consumption model

\section{Introduction}

As is shown in Figure 1 [1], China's megacity electric vehicles (EVs) industry has achieved rapid development under the dual incentives of government policy and financial subsidy in recent years. The government encourages and guides residents to purchase and use electric vehicles (EVs) through a variety of traffic administration policies, such as easing the purchasing permission and license plate restrictions. As a result, the number of electric vehicles in Beijing has seen a spurt of growth in the past two years. The sales of EVs in China accounted for half of all EV sales worldwide in 2017 [2]. According to forecasts, the number of electric vehicles in China will reach 5 million in 2020 and will exceed 50 million in 2030 [3]. In the meantime, the construction of related charging facilities and power network facilities showed a state of lagging development, which is difficult to meet the rapidly increasing charging demand. In order to alleviate the contradiction between rising demand for charging and insufficient supply of charging facilities, the government has promulgated relevant policies to promote the growth of charging facilities [4]. As Beijing's "Opinions on Further Strengthening the Construction and Management of Electric Vehicle Charging Infrastructure" launched in April 2019 clearly states that the number of charging facilities allocated to office buildings should not be less than 
one-fourth of the planned parking spaces, newly built residential areas must have a one to one parking lot charging pile which is a device installed on parking spaces to charge EVs [5].

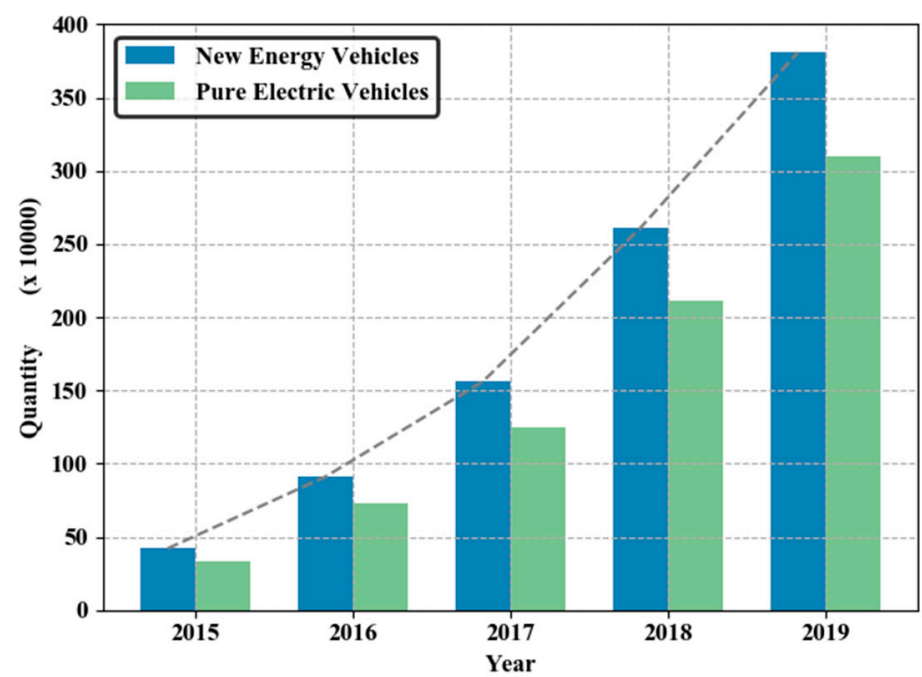

Figure 1. New energy vehicles and pure electric vehicles (EVs) in the last five years. New energy vehicles include EVs, hybrid EVs, and other clean energy vehicles [1].

Beijing's mall parking lots were equipped with charging facilities in 2018, but some problems were exposed. The ideal parking condition is that the EVs with charging needs are parked in the parking lot with the charging post, while the other cars are parked in the ordinary parking spaces. However, it was very common to observe that ordinary cars were parked in a parking space with a charging post. When the parking spot with the charging post is full, EVs cannot be charged, resulting in charging piles in the parking lot. In order to provide convenience for EV users in their daily use, their charging demand should be satisfied as much as possible. Therefore, to make the charging completion rate as high as possible, the EV charging management strategy needs to be designed in different situations.

With the development of EV industry, the convenience of EVs has been promoted [6-9], where EV charging strategies and location of charging stations have been addressed. In the EV parking charging scenario, the researches mainly focus on two aspects: charging efficiency and pricing policy. At present, many charging station operators choose to use the business model of energy transfer sales; but once fully charged, they do not encourage the drivers to move the vehicle out of the charging facility. Charging station operators are looking for ways to improve their operational efficiency. Learning from parking research [10], the introduction of time-based fees can help improve the efficiency of charging station capacity. As we all know, the charging rules of the parking lot will affect the charging decision of EV users [11]. Direct implementation of time-based fees may not be the best solution because it may interfere with the "parking charge" system; the advantages of EVs over other alternative fuel vehicles (AFVs) is that they can be charged while they are parked. There are big differences in the way EV drivers use public charging infrastructure. It depends on the location (for example, home or work) and the time of day [12]. In addition to these spatiotemperal differences, the parking and charging methods of drivers are also different [13]. Such differences may also affect the way time-based costs affect EV driver behavior. Tanguy et al. [14] proposed the concept of vehicle-to-building collaborative charging and used linear programming models to optimize parking charges. At present, some scholars have studied the implementation of vehicle-to-grid (V2G)and vehicle-to-building (V2B) in the fields of electronics [15], optimization [16,17], charge control [18], demand-side response [19], and uncertainty [20]. However, there are few papers that have analyzed the coupling between photovoltaic resources and electric vehicles in public buildings [21-25]. Due to strict restrictions on private parking and charging resources in residential areas of typical European cities, Schurmann, Timpner, and Wolf [26] proposed the EV protocol and integrated the protocol with the 
International Standards Organization (ISO) 15,118 standard. By using this method, it helps to reduce operating costs and improve the utilization of charging stations or EV power equipment. Lokesh and Min optimized the selection of EV charging stations through a real-time information sharing framework between EVs and charging stations, aiming to reduce average waiting time and improve customer service indicators.

It is also one of the research interests to schedule and plan the charging of EVs through price strategy [27]. Chang et al. [28] proposed a co-billing strategy based on the use of time-based billing services. By analyzing the driver's price response model, an optimal particle swarm optimization model for charging load and time-of-use price was established. The results show that the load distribution results are obviously better than the average load distribution. Xu et al. [29] conducted a case study in Guangdong Province, China, and proposed a mathematical model of a new layered framework that coordinates plug-in EV charging on multiple time scales (i.e., early and real-time). Common optimization of provincial, municipal and charging station-level charging strategies not only reduces the cost of charging but also meets the customer's charging requirements, which is very effective in reducing system peak demand and controlling charging costs. Qi et al. [30] proposed a distributed layered charging strategy and compared several different charging strategies by the Lagrangian relaxation method. It concludes that the proposed charging strategy is superior to other strategies.

However, very few researchers have noticed the mechanism on how the charging affects the decision making of moving vehicles after a full charge, and there is no clear charging model for increasing the utilization of parking spaces. The problem of random parking in public areas still exists. Facing the increasing number of EVs, the parking spaces of EVs in parking lots have not been fully utilized. The objective of this paper is the orderly parking of EVs for charging in a commercial parking lot by optimizing the utilization of the parking space. Based on the relationship between parking fee and parking need, a parking strategy based on fixed-penalty model and dynamic-penalty model is developed, and the simulation of orderly parking management with a mixture of parking space for ordinary cars and charging space for EVs is made. The scenario diagram of the scheduling system for a typical parking lot is shown in Figure 2.

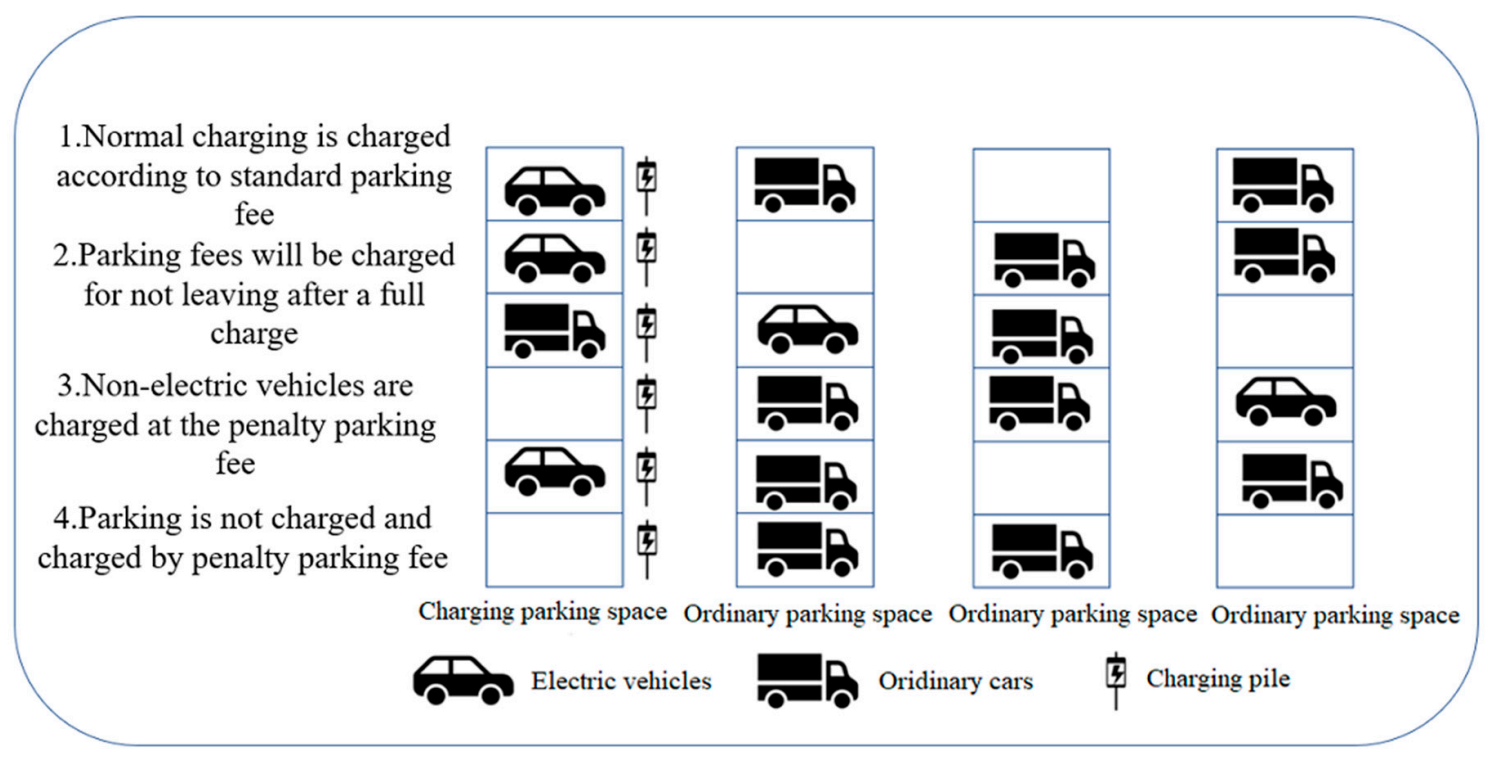

Figure 2. Charging scenario diagram of a parking lot.

\section{Orderly Operation Modeling of Charging Facilities in Parking Lot}

\subsection{Traffic Flow Model in Public Commercial Area}

In shopping malls, hospitals, scenic areas, and other public commercial areas, the arrival of each car can be regarded as an independent random event, and the mall traffic from the beginning of 
business to the end of the business period is viewed smoothly. Peaks also appear to be relatively flat, so the number of cars arriving at a parking lot in a public area can be considered as a random variable subject to Poisson distribution with probability distribution defined by:

$$
P(X=k)=\frac{\lambda^{k}}{k !} e^{-\lambda}
$$

where $X=k$ means that there are $k$ cars arriving in the parking lot per hour, and $\lambda$ means the average number of vehicles arriving in the parking lot. When the average daily traffic data of parking lots in public areas can be obtained, the Poisson distribution parameter $\lambda$ can be calculated by setting a reasonable time interval to get the traffic distribution model of parking lots in public areas. According to the National Household Travel Survey's data, people's travel probability density is a normal distribution [31]. Combined with the data on a certain shopping mall's passenger flow in Beijing from AutoNavi Map APP(AutoNavi Map APP is a mobile navigation software issued by China AutoNavi Software Co., Ltd.), when the unit time is one hour, the flow of people in the mall presents a form of a superposition of two normal distributions with different peaks over time. The peak times of the two normal distributions occur at 12:00 noon and 18:30, respectively, and the peak probability density of the latter is larger than that of the former, which means that the number of people arriving at the mall around 18:30 is the largest in a day. Thus, the time distribution of traffic flow in a mall parking lot can be modeled as:

$$
\begin{gathered}
f_{1}\left(x ; \mu_{1}, \sigma_{1}\right)=\frac{1}{\sigma_{1} \sqrt{2 \pi}} \exp \left(-\frac{\left(x-\mu_{1}\right)^{2}}{2 \sigma_{1}^{2}}\right), \\
f_{2}\left(x ; \mu_{1}, \sigma_{2}\right)=\frac{1}{\sigma_{2} \sqrt{2 \pi}} \exp \left(-\frac{\left(x-\mu_{2}\right)^{2}}{2 \sigma_{2}^{2}}\right), \\
f_{M}(x)=0.4 f_{1}\left(x ; \mu_{1}, \sigma_{1}\right)+0.6 f_{2}\left(x ; \mu_{2}, \sigma_{2}\right), \\
\text { s.t. } \quad 0<x \leq 24 .
\end{gathered}
$$

The shopping mall's passenger flow data in Beijing in the AutoNavi map (bar graph) and the traffic flow probability density in the shopping mall (by line) approximated by formulas (2)-(5) is shown in Figure 3.

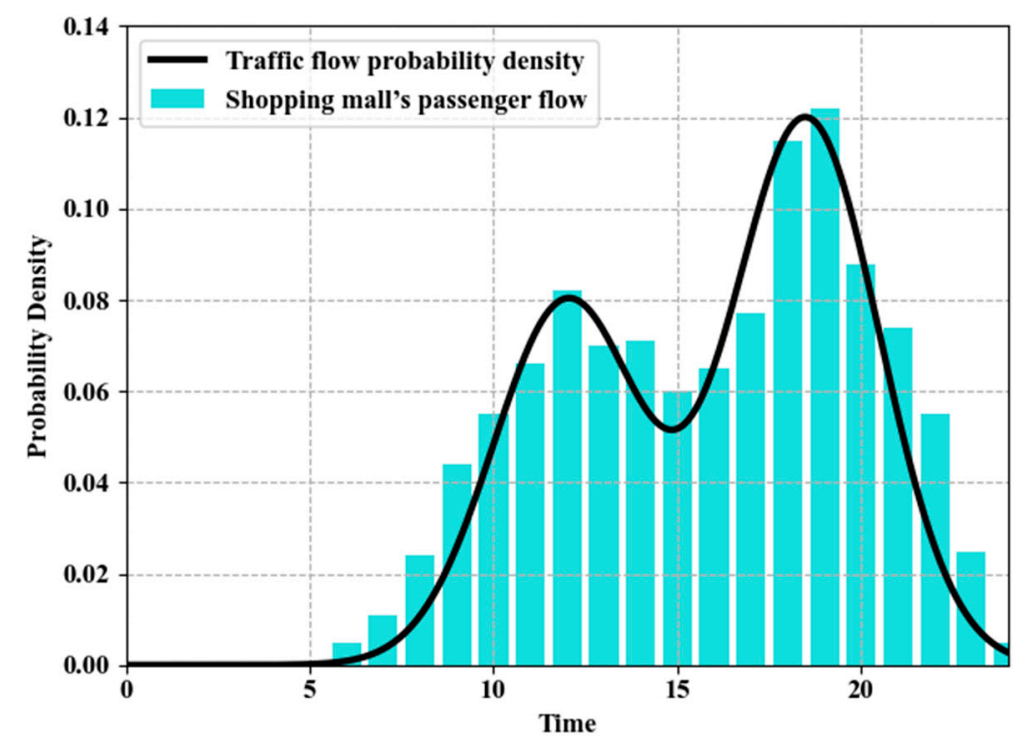

Figure 3. Shopping mall's passenger flow and approximated traffic flow probability density. 
Among them, $f_{1}\left(x ; \mu_{1}, \sigma_{1}\right)$ is the density function with the first small peak; the maximum appears at 12:00, and we can make $\mu_{1}=12$. At noon, traffic flow curve is relatively stable, and $\sigma_{1}$ can be 2 . The second density function $f_{2}\left(x ; \mu_{2}, \sigma_{2}\right)$ has the second small peak, and the maximum appears in 18:30; therefore, $\mu_{2}=18.5$. Traffic in evening hours is heavier than in the noontime, and $\sigma_{2}$ is taken as 1. Combining the two densisty functions, $f_{M}(x)$ is the distribution of traffic flow in shopping malls in one day, which is the superposition of two normal distributions at noon and evening. The time that cars stay in the parking lot of a shopping mall varies from half an hour to several hours, which can be regarded as evenly distributed.

\subsection{Parking Space Probability Model}

Unlike ordinary products, parking spaces are a commodity of great price elasticity. Pricing for different parking lots can vary widely. To determine the probability of a car being parked at random in a parking lot and the probability that an EV will be moved out after it is fully charged, we use the cost of the car owner being penalized. First, in a parking lot with a parking penalty, we define the probability that ordinary car owners and EV owners park their cars in the two parking spaces as:

$$
\begin{aligned}
& P_{o 2 E V}=\frac{\frac{c_{O 2 o}}{c_{O 2 o}+c_{O 2 E V}} \times \frac{N_{E V}}{N_{E V}+N_{o}}}{\frac{c_{O 2 o}}{c_{O 2 o}+c_{O 2 E V}} \times \frac{N_{E V}}{N_{E V}+N_{o}}+\frac{c_{O 2 E V}}{c_{O 2 o}+c_{O 2 E V}} \times \frac{N_{o}}{N_{E V}+N_{o}}}, \\
& P_{o 2 o}=\frac{\frac{c_{O 2 E V}}{c_{O 2 o}+c_{o 2 E V}} \times \frac{N_{o}}{N_{E V}+N_{o}}}{\frac{c_{E 2 o}}{c_{O 2 o}+c_{O 2 E V}} \times \frac{N_{O 2 E V}}{N_{E V}+N_{o}}+\frac{N_{o}}{c_{o 2 o}+c_{o 2 E V}} \times \frac{N_{E V}+N_{o}}{N_{E}}} \\
& P_{E V 2 o}=\frac{\frac{c_{E V 2 E V}}{c_{E V 2 o}+c_{E V 2 E V}} \times \frac{N_{o}}{N_{E V}+N_{o}}}{\frac{c_{E V 2 o}}{c_{E V 2 o}+c_{E V 2 E V}} \times \frac{N_{E V}}{N_{E V}+N_{o}}+\frac{c_{E V 2 E V}}{c_{E V 2 o}+c_{E V 2 E V}} \times \frac{N_{o}}{N_{E V}+N_{o}}}, \\
& P_{E V 2 E V}=\frac{\frac{c_{E V 2 o}}{c_{E V 2 o}+c_{E V 2 E V}} \times \frac{N_{E V}}{N_{E V}+N_{o}}}{\frac{c_{E V 2 o}}{c_{E V 2 o}+c_{E V 2 E V}} \times \frac{N_{E V}}{N_{E V}+N_{o}}+\frac{c_{E V 2 E V}}{c_{E V 2 o}+c_{E V 2 E V}} \times \frac{N_{o}}{N_{E V}+N_{o}}},
\end{aligned}
$$

where $P_{O 2 E V}$ is the probability of parking an ordinary car in a charging space, $P_{O 2 o}$ is the probability of parking an ordinary car in an ordinary parking space, $P_{E V 2 o}$ is the probability of parking an EV in an ordinary parking space, $P_{E V 2 E V}$ is the probability of parking an EV in a charging space, $c_{02 o}$ is the cost of an ordinary car parked in an ordinary parking space, $c_{02 E V}$ is the cost of ordinary cars parked in a charging space, $c_{E V 2 o}$ is the cost of an EV parked in an ordinary parking space, $c_{E V 2 E V}$ is the cost of an EV parked in a charging space, $N_{o}$ is the number of ordinary parking spaces in the mall parking lot, and $N_{E V}$ is the number of charging spaces in the mall parking lot.

The cost of parking fee can be calculated as:

$$
\mathcal{C}_{*}=\int_{T_{\text {arrivals }}}^{T_{\text {leave }}} p^{*}(t) d t,
$$

where $c_{*}$ is the cost of total parking fee under different parking models, $p^{*}(t)$ stands for parking fees per unit of time in this model, $T_{\text {arrival }}$ is the arrival time of the car, and $T_{\text {leave }}$ is the leave time of the car.

Then, we define the probability of an EV moving out after fully charged as:

$$
P_{m}=\frac{c_{p}-c_{u}}{c_{p}-c_{u}+c_{m}}
$$


where $P_{m}$ is the probability of moving out, and $C_{m}$ is the cost of moving a car from the charging space to other appropriate parking space. It is worth noting that $C_{m}$, the cost of moving a car, is often different from person to person. For the sake of convenience, we define it as a constant representing most people. $C_{p}$ is the cost of penalty, and $C_{n}$ is the cost without penalty.

As before, the cost of parking fee can be calculated as:

$$
c_{*}=\int_{T_{\text {present }}}^{T_{\text {lenve }}} p^{*}(t) d t
$$

what is different is that $T_{\text {present }}$ is current moment.

\subsection{Parking Response Willingness Model}

According to a large number of social survey data obtained from consumer psychological price stimulation of EV owners, the consumers will respond by the stimulus that has an acceptable range, generally $3-5$ times as the price difference. When the stimulus intensity is within the acceptable range, users will basically choose to accept or reject it according to their own preference. When the penalty rate is too high, EV users are less inclined to park in this parking spaces due to fear of high penalties. Therefore, the probability of whether EV users choose to park in the parking lot with penalty can be expressed as:

$$
P_{w p}=\exp ((-F(t)+12 t / 60)),
$$

where $F(t)$ is the parking fee that users should pay when they accept penalty, and $P_{w p}$ is the probability that the user facing the penalty amount to evaluate whether to enter the parking lot.

If the penalty is too low, it is close to the state of no penalty. All car users will choose to enter the parking lot and park at will, resulting in no charging piles for EVs to charge, and the utilization of charging parking spaces is reduced. Otherwise, if the penalty fee is too high, EV owners are worried about the higher overhead costs caused by not moving the vehicle after the charging is over, which will cause the owners to be unwilling to choose here for charging. To optimize the penalty factor that the users can accept, and find the maximum utilization rate within the range that the user can accept the penalty, we use a heuristic optimization algorithm, particle swarm optimization (PSO), which is a population based stochastic optimization technique developed by Eberhart and Kennedy in 1995 [32].

\subsection{Penalty Strategy Model}

The fee for shopping mall parking is divided into two parts, charging cost and parking fee. If an $\mathrm{EV}$ is charged, it will be charged for charging and parking. If there is no penalty, the fee only includes parking fees. Ordinary cars only have parking fees. Charging fees of the EVs are uniformly charged by the grid company. Parking lot can be set with different parking fees. In establishing a parking model, we consider 4 different parking-fee models shown in Figure 4, namely non-penalty model, fixed-penalty model, linear dynamic-penalty model, and non-linear dynamic-penalty model. In the United States, as the number of illegal driving increases, motorists will face more fines. This stepped penalty model is divided into two types: stepped incremental pricing model and stepped decreasing pricing model [33]. The greater the intensity of the penalty, the less likely the driver to break the law. Inspired by the literature [33], a new penalty model is proposed based on time-increasing penalty for the parking violation. The goal of the penalty model is to improve the utilization of charging space. This goal is achieved by setting a fine that increases over time to increase the driver's illegal parking cost, thereby reducing illegal parking behavior. The level of the penalty amount determines whether the driver will park illegally, but an excessive penalty amount will reduce the parking rate of all parking spaces in the parking lot. Therefore, four different parking fee models are proposed to take into account the tolerance and acceptance of the penalties of the majority of drivers. Fixed-penalty is based on the parking fee based on a fixed amount of penalty per hour. The maximum enforcement is to give users no buffer reminder time. Once parking violations occur, they will face higher penalty 
fees from the beginning. The amount of parking fees for dynamic-penalty gradually increases with the illegal parking time. When the illegal parking is within the specified time period, the parking fee slowly increases, and the user is given a buffer time to remind him that, when the illegal parking time exceeds the specified time period, the penalty amount will increase to the maximum intensity.
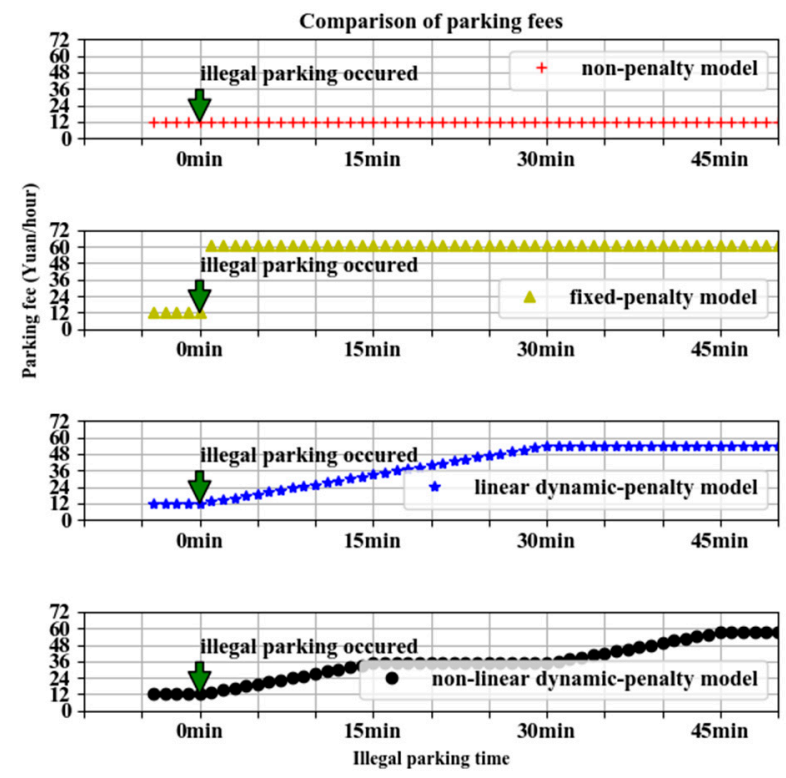

Figure 4. Comparison of parking fees in different models.

\subsubsection{Non-Penalty Model}

To set up a control group, the conventional charging strategy is used as non-penalty model. That is, if an ordinary car is parked on an EV charging space, or an EV is parked on a charging space without charging, there is no penalty. The numerical expression of the parking fee of non-penalty model is:

$$
F_{n p}=12 t \quad(t \geq 0)
$$

where $t$ is the illegal parking time, and 12 is the parking fee paid per hour.

\subsubsection{Fixed-Penalty Model}

Under this model, the ordinary cars parked in the charging spaces and the EVs that occupy the charging spaces without charging will be penalized by a fixed penalty, that is, parking fees will be several times more than the normal parking fees. The numerical expression of the parking fee of fixed-penalty model is, for example,

$$
F_{s p}=Q_{s} t+12 t(t \geq 0)
$$

where $t$ is the illegal parking time, and $Q_{s}$ is the fixed-penalty factor.

\subsubsection{Dynamic-Penalty Model}

Under this model, the vehicle that occupies the charging space under the non-charging condition is penalized by increasing rate. For linear dynamic-penalty model, the parking fee increases linearly from normal to several times within half an hour and then stays at the maximum limit. The numerical expression of the linear dynamic-penalty model is, for example,

$$
F_{l d p}=\left\{\begin{array}{lr}
Q_{d l} t^{2}+12 t & (0 \leq t \leq 0.5) \\
Q_{d l}(t-0.5)+0.25 Q_{d l}+12 t \quad(t>0.5)
\end{array}\right. \text { ， }
$$


where $t$ is the illegal parking time, and $Q_{d l}$ is the linear dynamic-penalty factor. The numerical expression of the non-linear dynamic-penalty model is, for example,

$$
F_{n l d p}=\left\{\begin{array}{lr}
Q_{d n 1} t^{2}+12 t, & (0 \leq t \leq 0.25) \\
0.5 Q_{d n 1}(t-0.25)+\frac{1}{16} Q_{d n 1}+12 t, & (0.25<t \leq 0.5) \\
Q_{d n 2}(t-0.5)^{2}+0.5 Q_{d n 1}(t-0.5)+\frac{3}{16} Q_{d n 1}+12 t, & (0.5<t \leq 0.75) \\
0.5\left(Q_{d n 1}+Q_{d n 2}\right)(t-0.75)+\frac{\left(5 Q_{d n 1}+Q_{d n 2}\right)}{16}+12 t, & (t>0.75)
\end{array}{ }^{\prime}\right.
$$

where $t$ is the illegal parking time, and $Q_{d n 1}, Q_{d n 2}$ are the non-linear dynamic-penalty factors.

\section{Optimization Model}

\subsection{Objective Functiaon}

The purpose of the optimization is to increase the utilization of charging parking spaces; thus, the objective function is defined as:

$$
\max \left\{f_{t}(x)\right\}=\max \left\{\eta=\frac{N_{c}}{N_{n}}\right\},
$$

where $\eta$ is the utilization of charging parking spaces, $N_{c}$ is the total number of EVs that have been charged, and $N_{n}$ is the total number of EVs that need charging.

Constraints to be satisfied are:

$$
\text { s.t. }\left\{\begin{array}{c}
\mathrm{Car}_{i} \in\{0,1\} \\
\mathrm{NOR}_{i} \in\{0,1\} \\
E V S_{i} \in\{0,1\} \\
E V C_{i} \in\{0,1\} \\
\operatorname{Soc}_{i} \in(0,1]
\end{array}\right.
$$

where $\mathrm{Car}_{i}$ is the property of the $i$-th car, 0 means ordinary car, and 1 means $\mathrm{EV}$; NOR $R_{i}$ is the status of the $i$-th normal parking space, 0 means idle, and 1 means occupied; $E V S_{i}$ is the status of the $i$-th charging parking space, 0 means idle, and 1 means occupied; $E V C_{i}$ is the charging state of the charging parking space, 0 means not charging, and 1 means charging; Soc $_{i}$ is the power of the $i$-th EV. In addition, the following constraint should be satisfied to guarantee that, when the state of the $i$-th charging parking space is charging, the state of the $i$-th charging parking space is occupied to charge an EV:

$$
\mathrm{Car}_{i} \times E V S_{i} \leq E V C_{i} .
$$

\subsection{Partical Swarm Optimization Algorithm}

In the PSO algorithm, the search process starts from a set of problem solutions rather than from a single individual. It has an implicit parallel search feature, thereby reducing the possibility of falling into a local minimum. And, because of this parallelism, it is easy to implement on a parallel computer to improve algorithm performance and efficiency. The particle swarm consists of particles, and the position of each particle represents the potential solution of the optimization problem in the D-dimensional search space.

The mathematical description of the PSO algorithm is as follows:

Each particle $i$ contains a D-dimensional position vector $X_{i}=\left(X_{i 1}, X_{i 2}, \cdots \cdots, X_{i D}\right)$ and velocity vector $V_{i}=\left(V_{i 1}, V_{i 2}, \cdots \cdots, V_{i D}\right)$. When the particle $i$ searches the solution space, it saves the searched best position experienced, $P_{i}=\left(P_{i 1}, P_{i 2}, \cdots \cdots, P_{i D}\right)$. At the beginning of each iteration, the particle adjusts its velocity vector to adjust its position according to its own inertia and experience and the 
group's best position experienced, $P_{g}=\left(P_{g 1}, P_{g 2}, \cdots \cdots, P_{g D}\right)$. The position and velocity of each particle are updated as follows:

$$
\begin{gathered}
V_{i d}^{t+1}=\omega V_{i d}^{t}+C_{1} r_{1}\left(P_{i d}^{t}-X_{i d}^{t}\right)+C_{2} r_{2}\left(P_{g d}^{t}-X_{i d}^{t}\right), \\
X_{i d}^{t+1}=X_{i d}^{t}+V_{i d}^{t+1},
\end{gathered}
$$

where $C_{1}$ and $C_{2}$ are constants, which are called acceleration factors; $r_{1}$ and $r_{2}$ are uniformly distributed random numbers in $[0,1]$, and $d$ is the dimension in $\mathrm{D}$ dimensional space; $\omega$ is the inertia weighting factor. Equation (21) consists of three parts. The first part is the original velocity of the particle. The larger the value, the more conducive to the global search. The smaller the value, the better the local search ability and the ability to balance the global and local search. The second part is the particle's own thinking showing that the particle's own experience is attracted to the current search tendency, and it is randomly adjusted by $C_{1} r_{1}$, which is the use of the accumulated experience of the particle, so that the particle has a sufficiently strong global search ability to avoid local minima. The third part is the process in which particles learn from other particles' experiences, indicating that the sharing of information and social collaboration between particles is randomly adjusted by $C_{2} r_{2}$, and is directly related to the position of $P_{g}$ and the domain topology of the population. Under the combined action of these three parts, the particles constantly adjust their speed and position according to their own experience and use the information sharing mechanism, so as to effectively reach for the best position to find the optimal solution.

The typical characteristics of shopping mall parking lots are large traffic volume, short stay time and relatively even distribution. The flow chart of the simulation optimization process is shown in Figure 5, where $\mathrm{T}$ is the simulation step length, that is, a simulation is performed every $\mathrm{T}$ minutes, and the internal information of the parking lot is counted and recorded, $\mathrm{N}$ is the number of simulations, $\mathrm{NT}$ is the total simulation time, and $\mathrm{n}$ is the number of EVs leaving at $t+1$. For the three different orderly charging models, the parking operation steps and the charging process update stage will be different in different models. The parking process in penalty model is shown in Figure 6.

When a driver who needs to park enters the parking lot, he will choose a parking space or a charging space according to the remaining EV power and parking lot penalty strategy. After being fully charged, the driver will choose whether or not to move the vehicle to avoid parking penalty. After repeated iterative simulations, the parking fee, charging fee and parking space utilization rate under different decisions are finally obtained. The parking space utilization rate is used as the objective function for optimization. During the optimization process, the charging standards will be adjusted to observe its changes, and the changes in parking space utilization rates under different penalty models will be compared, providing strategies for leading drivers to conduct standardized parking behaviors.

The PSO algorithm is used to solve the optimization problem (18)-(20). The specific process is shown below:

Input parameters: the penalty factor of different penalty strategies, the cost of moving the car.

Objective function: the average expected value of parking lot utilization.

- Step1: Initialize the population, the particle length is [penalty factor, the cost of moving the car], and the population size is 50 .

- Step2: Initialize the particle fitness, randomly generate the penalty factor and the cost of moving the car, calculate the average parking lot utilization according to the particle state, and calculate the optimal fitness of the population and the fitness of each particle.

- Step3: Update particle velocity.

- Step4: Update particle position.

- Step5: Update the particle individual optimal and global optimal.

- Step6: If the termination condition is met, return to the optimal particle position; otherwise, loop to Step3. 


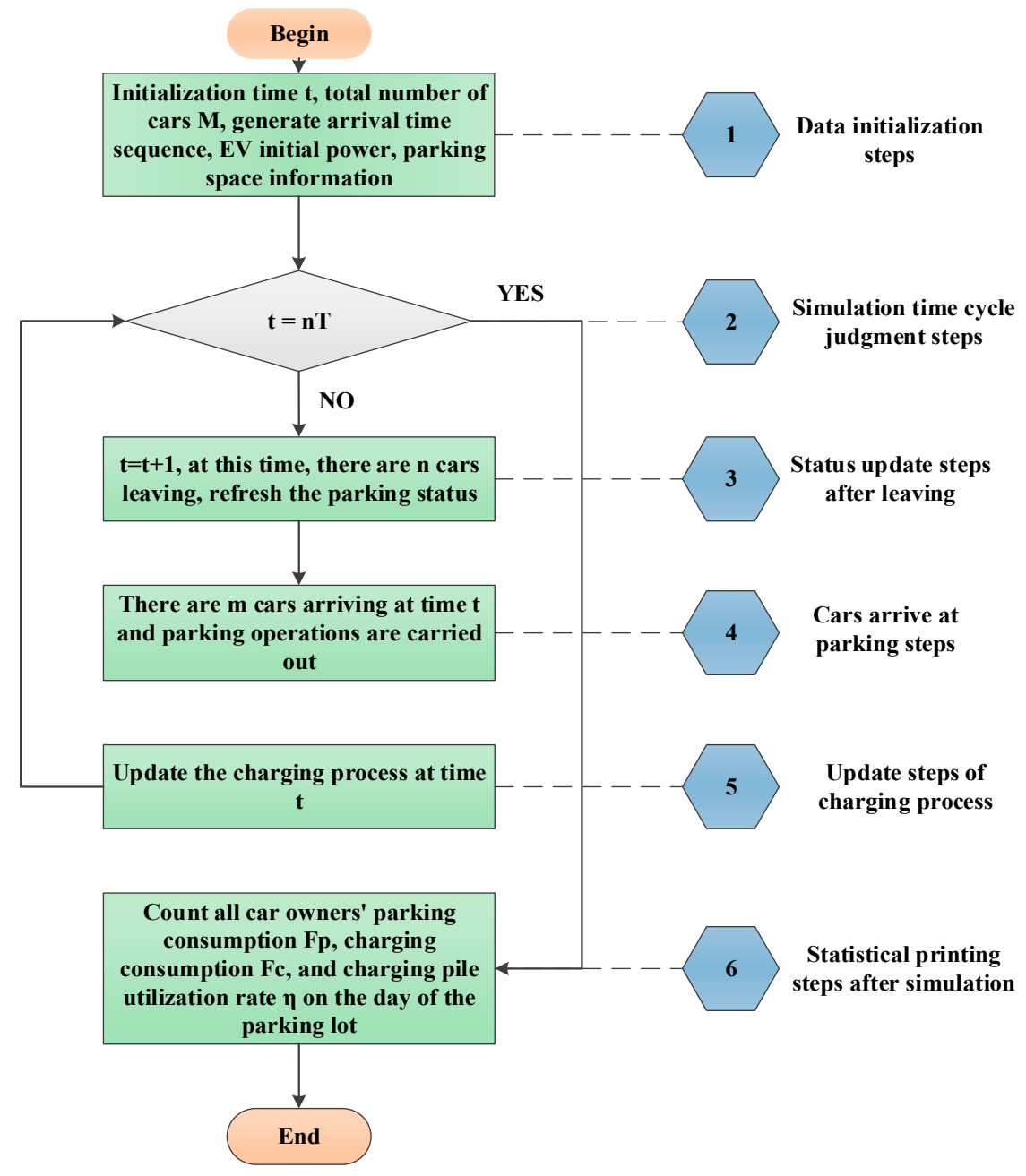

Figure 5. Simulation flowchart of shopping mall parking lot model.

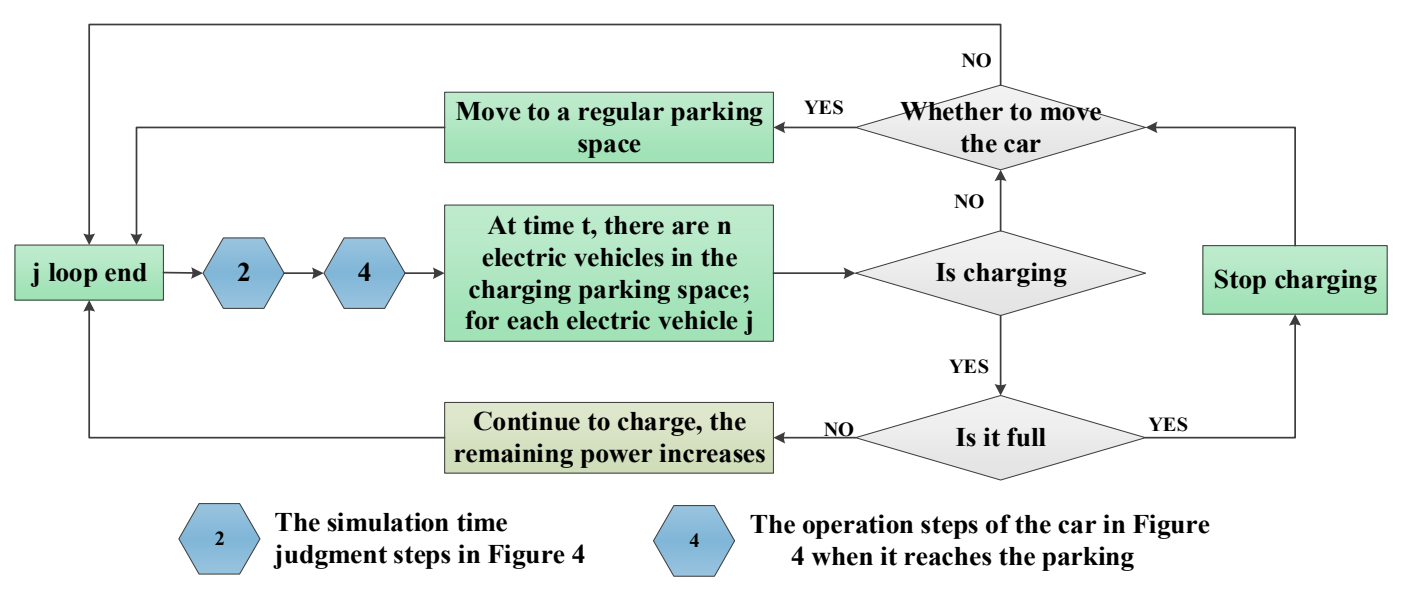

Figure 6. Flowchart of charging operation in penalty model.

\section{Numerical Case Studies}

\subsection{Problem Description}

The effects of the penalty models are studied in the public parking lots in the Changping District of Beijing. A total of 200 parking spaces were set up in a mall parking lot model, of which 20 parking spaces were dedicated for charging parking spaces, and the remaining 180 parking spaces were ordinary. 
As the parking lot is located in a busy business district, the traffic flow is very heavy. The limited charging parking spaces are often occupied by non-EVs, and even EVs are reluctant to leave after they are fully charged. At present, there is a lack of management of charging facilities, and many EVs with real charging needs cannot be served. Therefore, it becomes necessary to optimize the operation of charging facilities.

\subsection{Parameter Settings}

The charging pile is configured for fast charging. The power for fast charging is $30 \mathrm{~kW}$, and the battery capacity for electric vehicles is $60 \mathrm{kWh}$. According to the characteristics of the parking lot in the mall, the time for the car to stay in the parking lot is distributed evenly from $60 \mathrm{~min}$ to $150 \mathrm{~min}$ [34]. Assume that the mall opens at 9:00 am and closes at 10:00 pm and that the opening hours are $13 \mathrm{~h}$. During the period, the traffic distribution in the mall parking lot follows the Poisson distribution with key parameters given in Table 1.

Table 1. Main model parameters.

\begin{tabular}{cc}
\hline Model Parameters & Value \\
\hline Number of ordinary parking spaces & 180 \\
Number of charging parking spaces & 20 \\
Charging pile rated power & $30 \mathrm{~kW}$ \\
Electric vehicle battery capacity & $60 \mathrm{~kW}$ \\
Workday traffic & 1000 \\
Workday traffic distribution & $X \sim \pi(1.2821)$ \\
Weekend traffic & 1200 \\
Weekend traffic distribution & $X \sim \pi(1.5385)$ \\
Parking time distribution & $U(60,150)$ \\
\hline
\end{tabular}

The rapid development of EVs makes people pay more attention to the construction of charging infrastructure. In order to promote the construction of charging facilities, many regions in China have adopted policies related to financial subsidies. The specific billing strategies of each region are shown in Table 2. As shown in Figure 7, the government, charging facility operators and consumers are currently the three main players in China's EV charging market. The electricity sales and purchase costs of EVs are the most critical factors affecting the acceptable charging service fees. Besides, according to the relevant provisions of the State Grid Beijing Electric Power, the charging service fee for all periods is 0.8 Yuan $/ \mathrm{kWh}$, and the additional time-of-use charging fee is shown in Table 3.

Table 2. Charging service fees in some regions in China [35-37].

\begin{tabular}{cc}
\hline Regions & Regionl Policies \\
\hline $\begin{array}{c}\text { Beijing } \\
\text { Tianjin }\end{array}$ & $\begin{array}{r}\text { Operators set charging service fee on their own since April } 2018 \\
\text { No more than } 1.6 \text { yuan } / \mathrm{kWh} \text {. On a trial basis for one year } \\
\text { Electric bus charge service fee: } 06 \text { yuan } / \mathrm{kWh} .\end{array}$ \\
$\begin{array}{c}\text { Jinan } \\
\text { Other electric vehicle charge service fee: } 1.0 \mathrm{yuan} / \mathrm{kWh} \\
\text { charging service fee: } 0.60 \text { yuan } / \mathrm{kWh} \\
\text { charging service fee: } 0.95 \text { yuan } / \mathrm{kWh}\end{array}$ \\
$\begin{array}{r}\text { Hefei } \\
\text { Direct current (DC) fast charge pile service fee } 0.90 \text { yuan } / \mathrm{kWh} \text {. The alternating current }(\mathrm{AC}) \\
\text { charge pile service fee is } 30 \% \text { up and down in the quasi-price base of DC fast charge pile, } \\
\text { about } 0.63 \text { yuan } / \mathrm{kWh}\end{array}$ \\
\hline
\end{tabular}




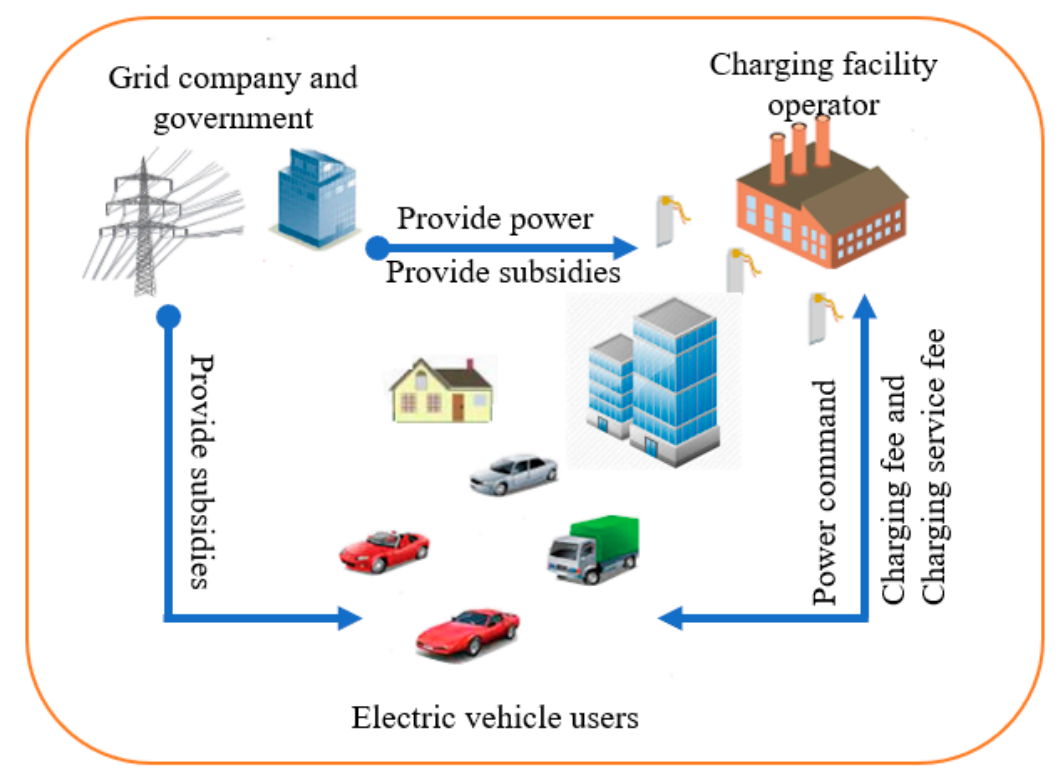

Figure 7. Diagram of the electric vehicle charging market.

Table 3. Time-of-use price for charging piles.

\begin{tabular}{ccc}
\hline Period & Price & Schedule \\
\hline \multirow{2}{*}{ Peak time } & \multirow{2}{*}{$1.044 \mathrm{Yuan} / \mathrm{kWh}$} & $10: 00-15: 00$ \\
& & $18: 00-21: 00$ \\
& & $7: 00-10: 00$ \\
Normal time & $0.6950 \mathrm{Yuan} / \mathrm{kWh}$ & $15: 00-18: 00$ \\
& & $21: 00-23: 00$ \\
Valley time & $0.3946 \mathrm{Yuan} / \mathrm{kWh}$ & $23: 00-7: 00$ \\
\hline
\end{tabular}

Considering the penetration of EVs, the number of EVs is a random integer between 100 and 150. The percentage of initial charge for each $\mathrm{EV}$ is a random number between $30 \%$ and $80 \%$. In the simulation, we set the time unit to $1 \mathrm{~min}$, and the total simulation time was set as 5 weeks. The basic parking fee is 12 Yuan per hour, and the cost of parking fee will be rounded up in every ten minutes.

The optimal utilization of EV parking spaces is calculated by PSO. The parameters of PSO are shown in Table 4 . The learning factors $C_{1}$ and $C_{2}$ are used to, respectively, determine the influence of their own experience and other particle's experience on their speed. Generally speaking, a better solution can be obtained when $C_{1}$ and $C_{2}$ are equal constants, and the value range is between 0 and 4 . In this article, the value of $C_{1}$ and $C_{2}$ is 1.49 . In (21), $\omega$ is called the inertia weight factor, which can adjust global optimization performance and local optimization performance [38]. As $₫$ increases, the global optimization performance of PSO is greater; as $₫$ decreases, the local optimization performance of PSO is better. According to the linearly decreasing rule in the search process, $\omega$ decreases in the range of $\{0.4,0.9\}$. The population size of the particles is $N$, and the particles lack the diversity for small $N$, so the PSO will easily converge to local optimum. A large $N$ can also lead to complicated and meaningless calculations. In this article, the value of $N$ is defined as 50 [39]. 
Table 4. Particle swarm optimization (PSO) parameters.

\begin{tabular}{ccc}
\hline Parameter & Symbol & Value \\
\hline Learning factor & $C_{1}$ & 1.49 \\
Learning factor & $C_{2}$ & 1.49 \\
Population size & $N$ & 50 \\
Maximum number of iterations & Kmax & 100 \\
Inertia weight & $\omega$ & 0.5 \\
\hline
\end{tabular}

\subsection{Result Analysis and Discussion}

Using the same initial data of vehicle behavior, simulation experiments were separately carried out using the non-penalty model, the fixed-penalty model and the dynamic-penalty model. The PSO algorithm is used to optimize the penalty factor parameters of the penalty model, And the results are shown in Table 5.

Table 5. Optimized penalty factor parameters.

\begin{tabular}{cc}
\hline Penalty Strategy Model & Parameter \\
\hline Fixed-penalty model & Qs $=49$ \\
Linear dynamic-penalty model & Qdl $=42$ \\
Non-linear dynamic-penalty model & Qdn1 $=43$, Qdn2 $=47$ \\
\hline
\end{tabular}

Five weeks of data are sampled to calculate the daily parking utilization rate. The average utilization rate of the five weeks is used as the objective function. The optimization result is shown in Figure 8. In the non-penalty model and the optimal penalty model, four indicators commonly considered by shopping malls and car owners are compared, namely parking fees, charging fees, toll space utilization rates, and the number of unserved EVs. The simulation results are shown in Figures 9-12.

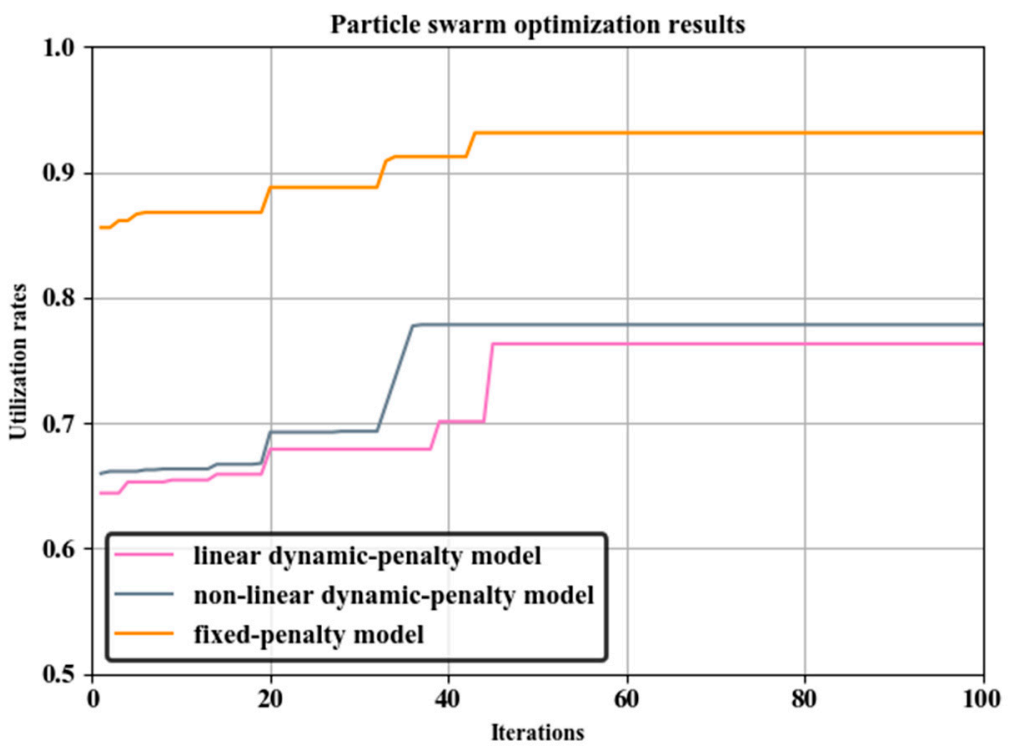

Figure 8. PSO results. 


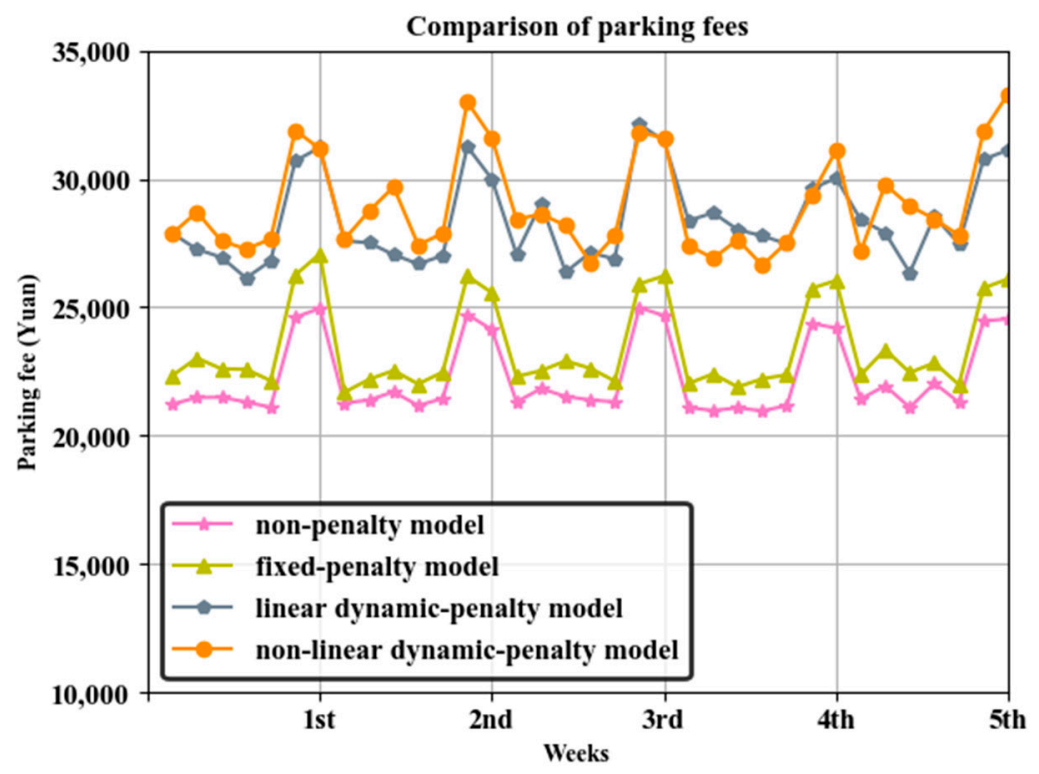

Figure 9. Comparison of parking fees.

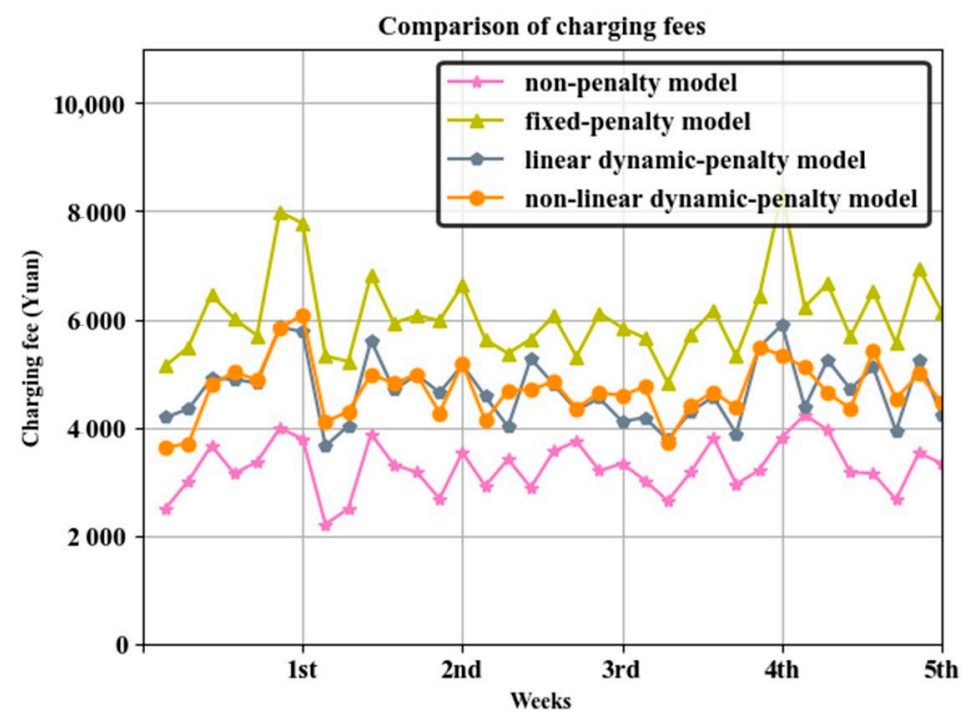

Figure 10. Comparison of charging fees.

As shown in Figure 8, after PSO iterative calculations, the parking utilization rates of the three different penalty models have increased. The charging space utilization rate of the fixed-penalty model is always better than that of the dynamic-penalty models, and the non-linear dynamic-penalty model is slightly better than the linear dynamic-penalty model. With the increase of interactions, the utilization rate of the fixed-penalty model stabilizes around 0.94, while the optimal utilization rate of the two dynamic-penalty models stabilizes around 0.78 . At the same time, by using the optimized penalty factor parameters in Table 5, when the best parameters are selected, compared with the non-penalty model (the utilization rate of electric vehicle parking spaces in the non-penalty model is about 0.42 , which can be obtained from the data in Table 6), the utilization rate of the penalty model has been significantly improved. This shows that increasing the penalty factor will increase the probability of car maneuvering, thereby increasing the utilization of charging spaces. 


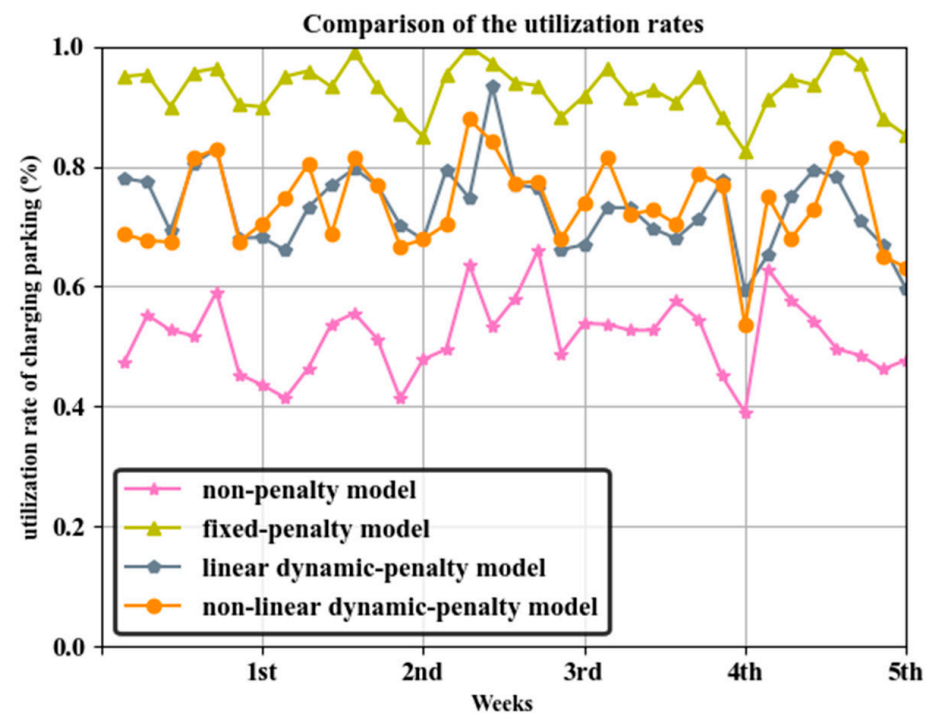

Figure 11. Comparison of the utilization rates.

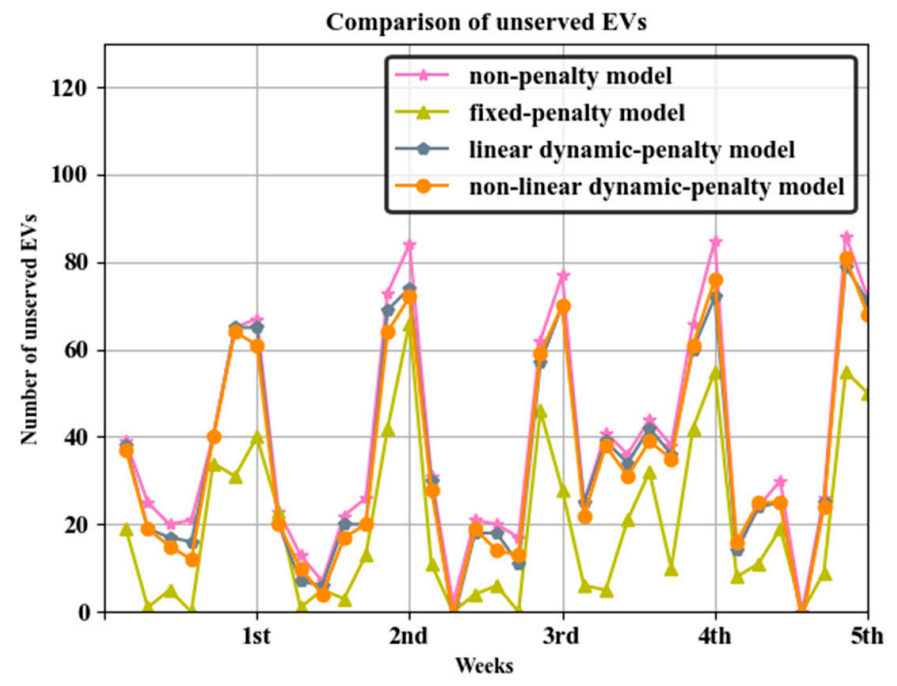

Figure 12. Comparison of unserved EVs.

Table 6. Comparison of indicators under the three optimized models.

\begin{tabular}{ccccc}
\hline $\begin{array}{c}\text { Orderly Parking } \\
\text { Charging Strategy }\end{array}$ & $\begin{array}{c}\text { Parking Fee } \\
\text { (Yuan) }\end{array}$ & $\begin{array}{c}\text { Charging Fee } \\
\text { (Yuan) }\end{array}$ & $\begin{array}{c}\text { Utilization } \\
\text { Rate (\%) }\end{array}$ & $\begin{array}{c}\text { Unserved } \\
\text { EVs }\end{array}$ \\
\hline Non-penalty model & 24546.00 & 3341.82 & 50.677 & 36.13 \\
Fixed-penalty model & 26102.00 & 6146.85 & 92.543 & 22.37 \\
Dynamic-penalty model & 32213.50 & 4467.86 & 73.351 & 33.54 \\
\hline
\end{tabular}

As can be seen from Figure 9, the parking fees in the non-penalty model are relatively balanced, with few fluctuations, and there are obvious differences on the workday and weekend. The daily average number of parking in the parking lot is 1000, and the average parking fee per vehicle is 24.5 Yuan. Compared with the non-penalty model, the fixed-penalty parking model has basically the same change in parking fees, and the average parking fee has increased by less than 2 Yuan. The parking fees of the dynamic-penalty models are much higher than that of the non-penalty model and the fixed-penalty model, and they have no steady pattern to cost fluctuations. The reason is that in the dynamic-penalty model, there is a transitional nature in the penalty region, which reduces the driver's willingness to move out. At the same time, it increases the probability of stopping at random within a short time. 
Figure 10 shows that the charging cost in the non-penalty model is basically maintained in the range of 2000 to 4000 yuan, and the difference between weekend and working days is not significant. The charging cost of the fixed-penalty model is much higher than that of the non-penalty model. The average daily charging cost reaches 6000 yuan, which means that more EVs are charged in this model. The charge for dynamic-penalty model is between non-penalty model and fixed-penalty model.

Figure 11 shows the comparison of the charging space utilization rates under four different strategies. The charging space utilization index is the key to the optimization of penalty models. Through the five-week simulation, the average utilization rate of the charging spaces is $50.7 \%$ in the non-penalty model, which means that the illegal occupancy of the charging spaces is very serious. In the fixed-penalty model, the average utilization rate of the charging spaces reached $92.5 \%$, and there is less occurrence of the situation that the EVs that need to be charged cannot be served. The average utilization rate of the dynamic-penalty model is $73.4 \%$. There is still much room for improvement.

As can be seen from Figure 12, there is a significant difference in the number of unserved EVs between the workday and the weekend. However, the trend of unserved EVs in the four models is basically the same. The fixed-penalty model is still the best performing strategy. The overall situation is better than the non-penalty model and the dynamic-penalty models. The number of unserved EVs in the non-penalty model is the highest.

As can be seen from the comparison figures, the results of different strategies in four indicators showed the characteristics of stratification. Since the results of linear dynamic-penalty model and non-linear dynamic-penalty model are similar in various indices, we describe them as dynamic-penalty model, and their average is compared with non-penalty model and fixed-penalty model in Table 6.

With the development of technology and the increase in the number of EVs, the demand for high-power charging facilities is becoming stronger. In the future, the charging power of charging piles will gradually increase, and the popularity and application of high-power charging piles will further shorten the charging time. At the same time, with the gradual increase in the number of EV users, facing the pressure of the shortage of parking spaces, parking lots need to increase the number of EV parking spaces. However, due to the current gasoline-fueled vehicles still occupying a dominant position, and the use of parking spaces is limited, there will be no substantial increase in parking spaces for EVs in near future. To further increase the utilization rate and reduce the number of unserved EVs, it is particularly necessary to combine punitive measures with increasing EV spaces and increasing the charging power of charging facilities. Therefore, based on the penalty model, this paper compares the impact of increasing charging power and increasing EV parking spaces on the utilization rate and the number of unserved EVs, respectively. The simulation results are shown in Figures 13 and 14.

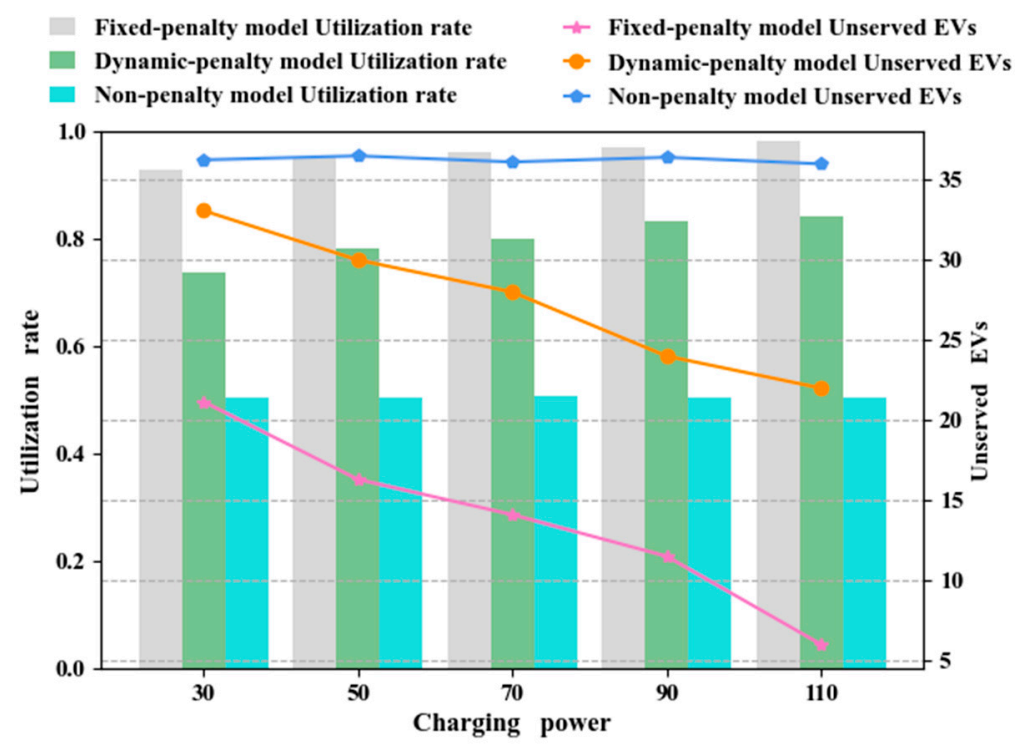

Figure 13. The impact of improving charging facilities' output power on unserved EVs and utilization. 


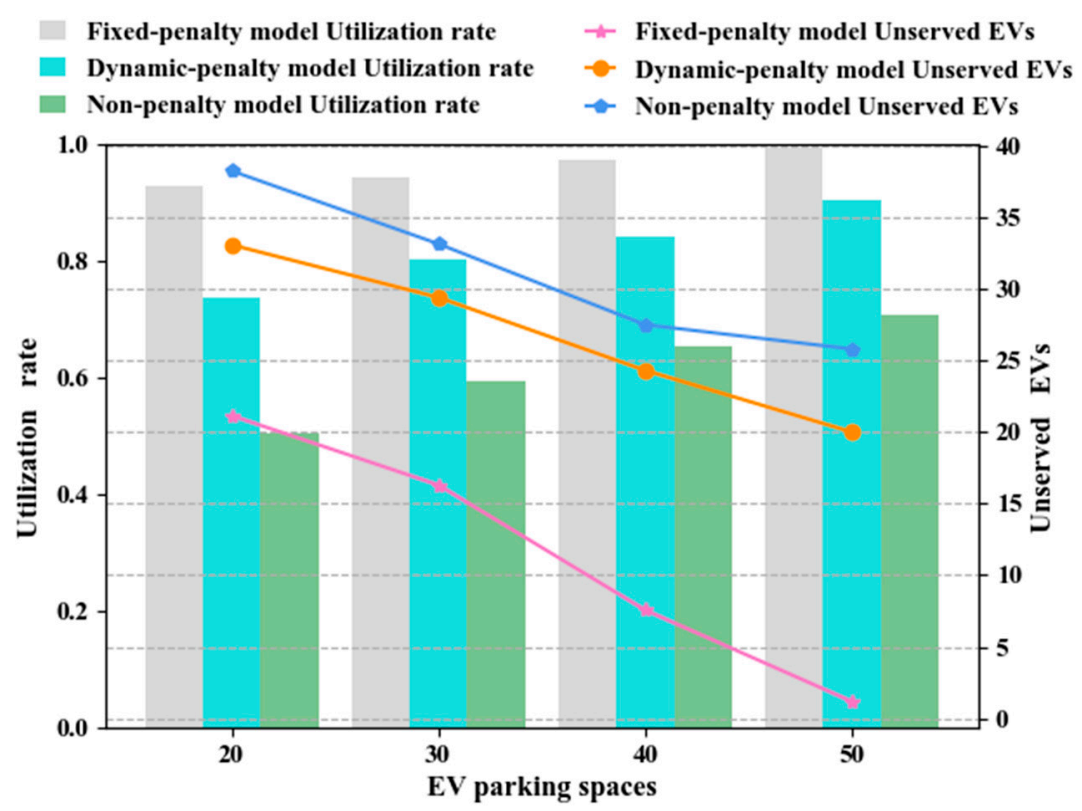

Figure 14. The impact of increasing EV parking spaces on unused EVs and utilization.

As shown in Figure 13, when the charging power is increased from $30 \mathrm{KW}$ to $110 \mathrm{KW}$, the fixed-penalty shows the highest utilization rate. Its value increases from $92.5 \%$ to $98.3 \%$, and the number of unserved EVs is reduced from 22 to 6 . In dynamic-penalty model, the utilization rate increased from $73.4 \%$ to $84.1 \%$, and the number of unserved EVs is reduced from 33 to 22 . For the non-penalty model, since there is no penalty for EVs to stay in the charging space after being fully charged, increasing the charging power will not affect the utilization rate and the number of unserved EVs.

As shown in Figure 14, when the parking spaces for EVs are increased from 20 to 50, the fixed-penalty can still better improve the utilization rate and reduce the number of unserved EVs. The utilization rate increases from $92.5 \%$ to $99.3 \%$. The number of unserved EVs decreased from 22 to 1 ; the utilization rate of dynamic-penalty increased from $73.4 \%$ to $90.5 \%$, and the number of unserved vehicles was reduced from 33 to 20. The expansion of parking spaces for EVs under the non-penalty model will also help increase the utilization rate and reduce the number of unserved EVs. The utilization rate has increased from $50.7 \%$ to $70.7 \%$, and the number of unversed EVs has been reduced from 36 to 26 . It can be seen under the non-penalty that, although the utilization rate of EV parking spaces has been improved, and the number of unserved EVs have also been reduced, there is still a large gap compared with the penalty. Therefore, based on the penalty model, further increasing the parking lot of EV charging spaces can better improve the utilization rate of EVs. However, for parking lots that cannot expand EV charging spaces, effective use of penalties can also greatly increase the utilization rate of EV charging spaces.

\section{Conclusions}

At present, many parking lots in public areas have a low utilization rate of charging spaces. Based on this, this paper proposes three penalty strategy models for parking in the charging space. Taking the utilization rate of charging spaces as the objective function, the penalty factors in the penalty models are optimized through the particle swarm optimization algorithm. By comparing four different penalty methods, adopting an appropriate penalty strategy model can significantly improve the utilization rate of charging spaces.

In applying penalties, the fixed-penalty model has a better optimization effect than the dynamicpenalty models. In the actual rulemaking, the fixed-penalty model can be used first to guide an orderly 
transition. After the EV drivers have formed the habits of orderly parking and charging, we can then move into a dynamic-penalty model that will improve the satisfaction of parking and charging.

For some shopping mall parking lots that have been built, the fixed-penalty model proposed in this article can be used to penalize drivers who do not move their cars after being fully charged. After they adapt to the penalty measures, dynamic-penalty models can be used to improve their satisfaction degree. For a shopping mall parking lot in the planning stage, the analysis of the charging power and the number of EV parking spaces in Figures 13 and 14 can be integrated, and the penalty measures suitable for the parking lot of the shopping mall can be selected and the number of charging spaces can be planned.

Author Contributions: Conceptualization, R.S. and K.Y.L.; methodology, R.S. and J.Z.; software, J.Z.; validation, H.S. and K.Y.L.; formal analysis, R.S. and J.Z.; investigation, Z.L.; resources, Z.L.; data curation, J.Z. and H.S.; writing_original draft preparation, R.S., J.Z., and H.S.; writing—review and editing, R.S., J.Z., and H.S.; visualization, J.Z. and H.S.; supervision, R.S.; project administration, R.S.; funding acquisition, R.S. All authors have read and agreed to the published version of the manuscript.

Funding: This paper is supported by National Natural Science Foundation of China under Grant 61203100 and the Fundamental Research Funds for the Central Universities under Grant 16MS42.

Conflicts of Interest: The authors declared that they have no conflicts of interest to this work.

\section{Nomenclature}

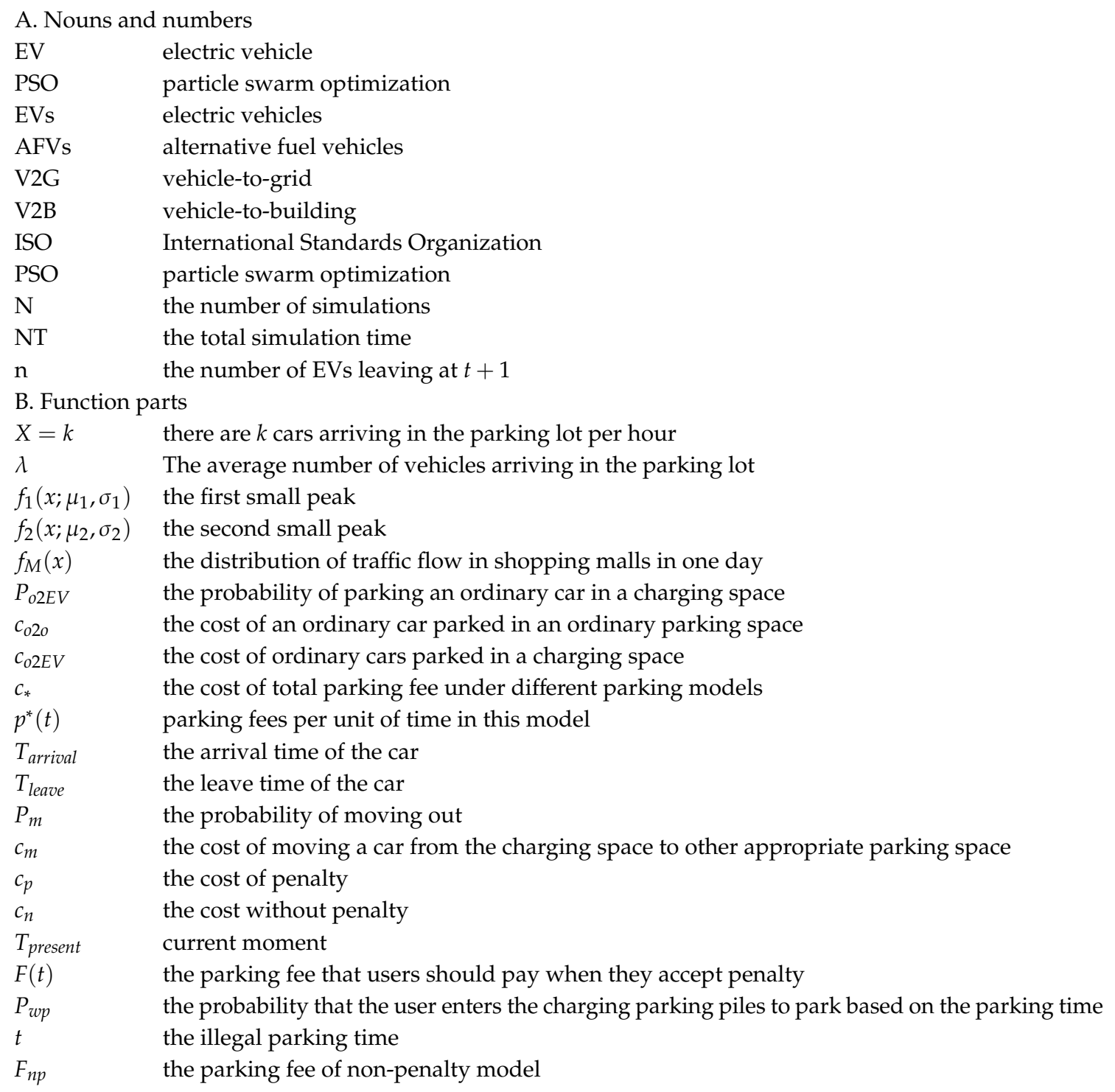




$\begin{array}{ll}F_{s p} & \text { the parking fee of fixed-penalty model } \\ Q_{s} & \text { the fixed-penalty factor } \\ F_{l d p} & \text { the linear dynamic-penalty model } \\ Q_{d l} & \text { the linear dynamic-penalty factor } \\ F_{n l d p} & \text { the non-linear dynamic-penalty model } \\ Q_{d n 1}, Q_{d n 2} & \text { the non-linear dynamic-penalty factors. } \\ \max \left\{f_{t}(x)\right\} & \text { the objective function } \\ \eta & \text { the utilization of charging parking spaces } \\ N_{c} & \text { the total number of EVs that have been charged } \\ N_{n} & \text { the total number of EVs that needed charging } \\ \mathrm{s.t} & \text { constraints to be satisfied } \\ C_{a r} & \text { the property of the } i \text {-th car } \\ N O R_{i} & \text { the status of the } i \text {-th normal parking space } \\ E V S_{i} & \text { the status of the } i \text {-th charging parking space } \\ E V C_{i} & \text { the charging state of the charging parking space } \\ S_{o c} & \text { the power of the } i \text {-th EV } \\ C_{1}, C_{2} & \text { Learning factor } \\ \varpi & \text { the inertia weight factor } \\ \mathrm{Kmax}_{N} & \text { Maximum number of iterations } \\ N & \text { Population size } \\ r_{1}, r_{2} & \text { random numbers in [0, } 1]\end{array}$

\section{References}

1. The Number of Private Cars Nationwide Exceeded 200 Million for the First Time, and New Energy Vehicles Reached 3.81 Million. Available online: http://www.ce.cn/xwzx/gnsz/gdxw/202001/07/t20200107_34064649. shtml (accessed on 25 August 2020).

2. Chu, W.; Im, M.; Song, M.R.; Park, J. Psychological and behavioral factors affecting electric vehicle adoption and satisfaction: A comparative study of early adopters in China and Korea. Transp. Res. Part D Transp. Environ. 2019, 76, 1-18. [CrossRef]

3. Yang, W.; Yan, Z.; Xinyang, H.; Yangiia, L.; Jun, Y.; Yingqing, R. Prediction of electric vehicle market based on market segmentation and regional gradient development. In Proceedings of the IEEE Conference on Energy Internet and Energy System Integration (EI2), Beijing, China, 26-28 November 2017.

4. National Development and Reform Commission. Electric Vehicle Charging Infrastructure Development Guidelines (2015-2020). Available online: http://www.gov.cn/zhengce/2015-10/09/content_5076250.htm (accessed on 25 August 2020).

5. The General Office of the Beijing Municipal People's Government. Implementation Opinions on Further Strengthening the Construction and Management of Electric Vehicle Charging Infrastructure. Available online: http://www.beijing.gov.cn/zhengce/zhengcefagui/201905/t20190522_60384.html (accessed on 25 August 2020).

6. Liu, D.; Wang, Y.; Shen, Y. Electric Vehicle Charging and Discharging Coordination on Distribution Network Using Multi-Objective Particle Swarm Optimization and Fuzzy Decision Making. Energies 2016, 9, 186. [CrossRef]

7. King, C.; Datta, B. EV charging tariffs that work for EV owners, utilities and society. Electr. J. 2018, 31, $24-27$. [CrossRef]

8. Honma, Y.; Kuby, M. Node-based vs. path-based location models for urban hydrogen refueling stations: Comparing convenience and coverage abilities. Int. J. Hydrog. Energy 2019, 44, 15246-15261. [CrossRef]

9. An, K.; Song, K.-B.; Hur, K. Incorporating Charging/Discharging Strategy of Electric Vehicles into Security-Constrained Optimal Power Flow to Support High Renewable Penetration. Energies 2017, 10, 729. [CrossRef]

10. Xu, P.; Li, J.; Sun, X.; Zheng, W.; Liu, H. Dynamic Pricing at Electric Vehicle Charging Stations for Queueing Delay Reduction. In Proceedings of the 37th IEEE International Conference on Distributed Computing Systems (ICDCS), Atlanta, GA, USA, 5-8 June 2017.

11. Wen, Y.; Mackenzie, D.; Keith, D.R. Modeling the charging choices of battery electric vehicle drivers by using stated preference data. Transp. Res. Rec. J. Transp. Res. Board 2016, 2572, 47-55. [CrossRef] 
12. Helmus, J.; Van Den Hoed, R. Unraveling User Type Characteristics: Towards a Taxonomy for Charging Infrastructure. World Electr. Vehicle J. 2015, 7, 589-604. [CrossRef]

13. Franke, T.; Krems, J.F. Understanding charging behaviour of electric vehicle users. Transp. Res. Part F Traffic Psychol. Behav. 2013, 21, 75-89. [CrossRef]

14. Tanguy, K.; Dubois, M.R.; Lopez, K.L.; Gagné, C. Optimization model and economic assessment of collaborative charging using Vehicle-to-Building. Sustain. Cities Soc. 2016, 26, 496-506. [CrossRef]

15. Zheng, Y.; Niu, S.; Shang, Y.; Shao, Z.; Jian, L. Integrating plug-in electric vehicles into power grids: A comprehensive review on power interaction mode, scheduling methodology and mathematical foundation. Renew. Sust. Energy Rev. 2019, 112, 424-439. [CrossRef]

16. Pearre, N.S.; Ribberink, H. Review of research on V2X technologies, strategies, and operations. Renew. Sust. Energy Rev. 2019, 105, 61-70. [CrossRef]

17. Li, Y.; Li, K.; Xie, Y.; Liu, J.; Fu, C.; Liu, B. Optimized charging of lithium-ion battery for electric vehicles: Adaptive multistage constant current-constant voltage charging strategy. Renew. Energy 2020, 146, 2688-2699. [CrossRef]

18. Zhang, W.; Gandhi, O.; Quan, H.; Rodríguez-Gallegos, C.D.; Srinivasan, D. A multi-agent based integrated volt-var optimization engine for fast vehicle-to-grid reactive power dispatch and electric vehicle coordination. Appl. Energy 2018, 229, 96-110. [CrossRef]

19. Modarresi Ghazvini, A.; Olamaei, J. Optimal sizing of autonomous hybrid PV system with considerations for V2G parking lot as controllable load based on a heuristic optimization algorithm. Sol. Energy 2019, 184, 30-39. [CrossRef]

20. Liu, K.; Wang, J.; Yamamoto, T.; Morikawa, T. Exploring the interactive effects of ambient temperature and vehicle auxiliary loads on electric vehicle energy consumption. Appl. Energy 2018, 227, 324-331. [CrossRef]

21. Barone, G.; Buonomano, A.; Forzano, C.; Giuzio, G.F.; Palombo, A. Increasing self-consumption of renewable energy through the Building to Vehicle to Building approach applied to multiple users connected in a virtual micro-grid. Renew. Energy 2020, 159, 1165-1176. [CrossRef]

22. Doroudchi, E.; Alanne, K.; Okur, Ö.; Kyyrä, J.; Lehtonen, M. Approaching net zero energy housing through integrated EV. Sust. Cities Soc. 2018, 38, 534-542. [CrossRef]

23. Thomas, D.; Deblecker, O.; Ioakimidis, C.S. Optimal operation of an energy management system for a grid-connected smart building considering photovoltaics' uncertainty and stochastic electric vehicles' driving schedule. Appl. Energy 2018, 210, 1188-1206. [CrossRef]

24. Quddus, M.A.; Shahvari, O.; Marufuzzaman, M.; Usher, J.M.; Jaradat, R. A collaborative energy sharing optimization model among electric vehicle charging stations, commercial buildings, and power grid. Appl. Energy 2018, 229, 841-857. [CrossRef]

25. Buonomano, A.; Calise, F.; Cappiello, F.L.; Palombo, A.; Vicidomini, M. Dynamic analysis of the integration of electric vehicles in efficient buildings fed by renewables. Appl. Energy 2019, 245, 31-50. [CrossRef]

26. Schurmann, D.; Timpner, J.; Wolf, L. Cooperative Charging in Residential Areas. IEEE Trans. Intellig. Transp. Syst. 2017, 18, 834-846. [CrossRef]

27. Dong, X.; Mu, Y.; Xu, X.; Jia, H.; Wu, J.; Yu, X.; Qi, Y. A charging pricing strategy of electric vehicle fast charging stations for the voltage control of electricity distribution networks. Appl. Energy 2018, 225, 857-868. [CrossRef]

28. Chang, F.; Huang, M.; Zhang, W.; Bao, Y.; Sun, B. A coordinated charging strategy for PV-Assisted charging station of electric vehicles based on charging service price. In Proceedings of the IEEE Asia-Pacific Transportation Electrification Conference and Exposition (ITEC Asia-Pacific), Harbin, China, 2-5 August 2017.

29. Xu, Z.; Su, W.; Hu, Z.; Song, Y.; Zhang, H. A Hierarchical Framework for Coordinated Charging of Plug-In Electric Vehicles in China. IEEE Trans. Smart Grid 2016, 7, 428-438. [CrossRef]

30. Qi, W.; Xu, Z.; Shen, Z.-J.M.; Hu, Z.; Song, Y. Hierarchical Coordinated Control of Plug-in Electric Vehicles Charging in Multifamily Dwellings. IEEE Trans. Smart Grid 2014, 5, 1465-1474. [CrossRef]

31. US. Department of Transportation Federal Administration. Available online: http://nhts.ornl.gov/download. shtml (accessed on 2 November 2020).

32. Coello Coello, C.A.; Reyes-Sierra, M. Multi-Objective Particle Swarm Optimizers: A Survey of the State-of-the-Art. Int. J. Computat. Intel. Res. 2006, 2, 287-308. [CrossRef] 
33. Billings, R.B.; Agthe, D.E. Price Elasticities for Water: A Case of Increasing Block Rates: Reply. Land Econ. 1981, 57, 276. [CrossRef]

34. Collin, A.J.; Xu, X.; Djokic, S.Z.; Moller, F.; Meyer, J.; Kutt, L.; Lehtonen, M. Survey of harmonic emission of electrical vehicle chargers in the European market. In Proceedings of the International Symposium on Power Electronics, Electrical Drives, Automation, and Motion (SPEEDAM), Anacapri, Italy, 22-24 June 2016.

35. Charging Service Fees for Electric Vehicles Everywhere. Available online: https://www.sohu.com/a/57149794_ 377299 (accessed on 2 November 2020).

36. National Development and Reform Commission Promulgated Electricity Price Policy for Electric Vehicles. Available online: http://www.gov.cn/xinwen/2014-07/30/content_2726804.htm (accessed on 2 November 2020).

37. Zhang, L.; Yang, M.; Zhao, Z. Game analysis of charging service fee based on benefit of multi-party participants: A case study analysis in China. Sustain. Cities Soc. 2019, 48, 101528. [CrossRef]

38. Yang, J.; He, L.; Fu, S. An improved PSO-based charging strategy of electric vehicles in electrical distribution grid. Appl. Energy 2014, 128, 82-92. [CrossRef]

39. Clerc, M. The swarm and the queen: Towards a deterministic and adaptive particle swarm optimization. In Proceedings of the 1999 Congress on Evolutionary Computation-CEC99 (Cat. No. 99TH8406), Washington, DC, USA, 6-9 July 1999.

Publisher's Note: MDPI stays neutral with regard to jurisdictional claims in published maps and institutional affiliations. 